\title{
Percutaneous Removal of Difficult Pulmonary Artery Foreign Body: A Rare Case Report
}

\author{
Umar Hayat MD ${ }^{1}$, Saba Afroz $\mathrm{MD}^{2}$, Abdur Rehman, $\mathrm{MD}^{3}$ \\ ${ }^{1}$ Wayne State University, Detroit, Michigan \\ ${ }^{2}$ Spectrum Health, Grand Rapids, Michigan \\ ${ }^{3}$ Mercy Health, Saint Mary's Grand Rapids, Michigan
}

\begin{abstract}
Endovascular catheterization is now more frequently used for various endovascular procedures and central venous access. Sometimes, catheterization causes rare complication when parts of the catheter break and can embolize to the main heart chambers, main pulmonary arteries and to other vascular sub-branches as a foreign body and can cause thrombophlebitis, endocarditis, vascular occlusion and thrombosis [1]. Migrated pulmonary artery foreign bodies are rare life threatening conditions and earliest reported in literature over 50 years ago (2). It carries a high mortality and morbidity if the foreign body is not removed timely (3). Surgical and nonsurgical methods for removal of these foreign bodies have been described in the past (4). Percutaneous removal is highly effective with a low complication rate and should be the first line intervention (5). One of the most commonly used device is a single loop snare, but sometimes it may be hard to retrieve the foreign body with single loop snare. In this case, we report the successful percutaneous retrieval of the broken catheter guide wire from the pulmonary artery by using multiple loop snare devices.
\end{abstract}

Keywords: Foreign body, percutaneous removal, snare

\section{Case Presentation}

A 78-year-old female with history of chronic kidney disease presented with acute kidney injury requiring urgent dialysis during the hospitalization. She went to operating room for placement of temporary dialysis access through right internal jugular vein. During the procedure piece of guide wire broke off and migrated in the heart, attempts were made to retrieve with various snares in operating room without success and lead to migration of the wire into pulmonary artery (arrow, image 1). Patient was taken emergently to cardiac catheterization laboratory. Temporary pacing wire was inserted through right femoral vein that is seen in all images. Swan-Ganzcatheter was advanced through right internal jugular access site that is seen in image 1a. Swan-Ganzcatheter was exchanged for multipurpose guide catheter that can be seen in all images. Snare with 3 interlaced loops (arrow, image 2) was advanced through multipurpose catheter. Broken piece of guide wire in pulmonary artery was engaged and removed with careful manipulation. Temporary pacing wire was removed and patient remained in stable condition post procedure. Attached video shows final phase of the procedure.

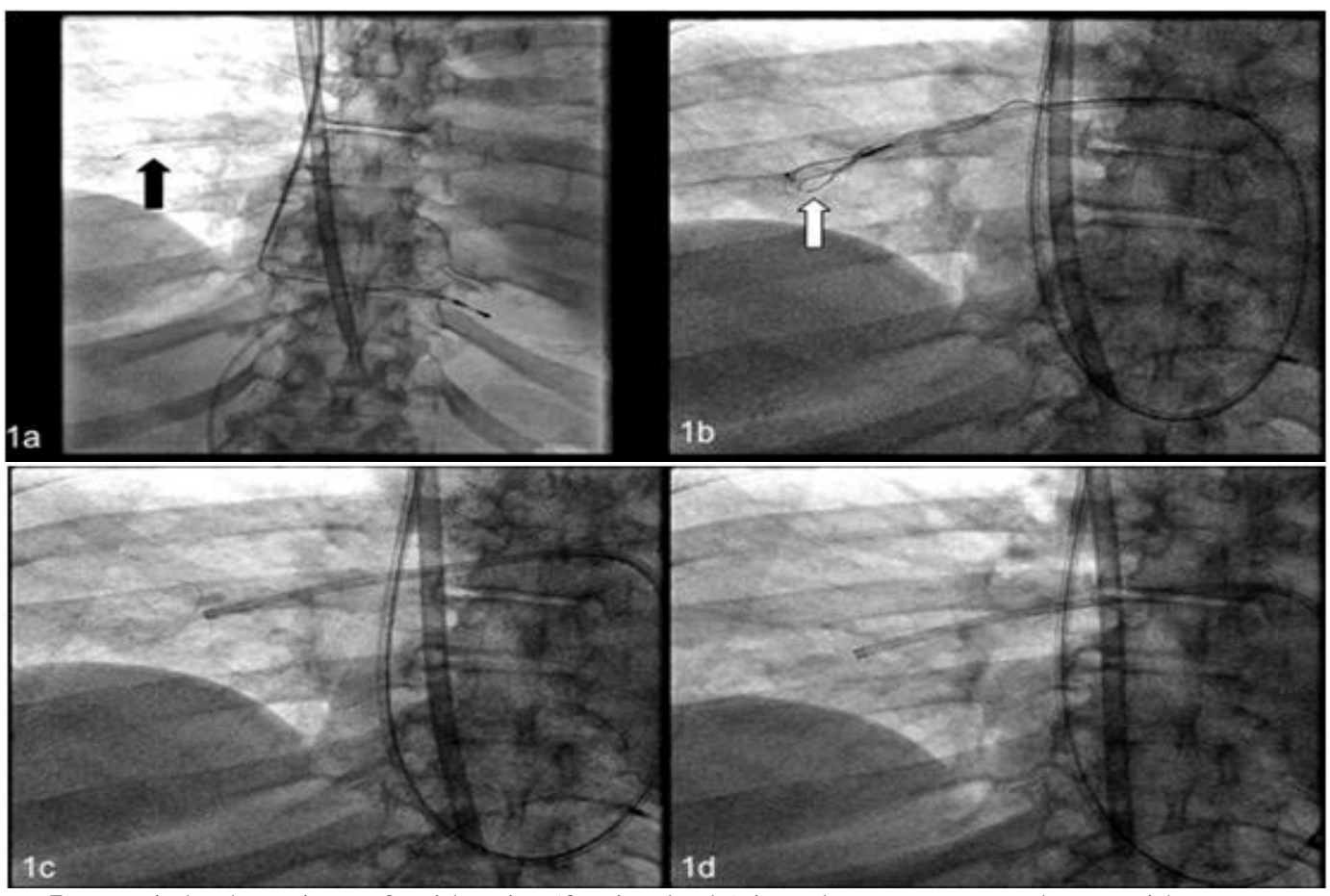

Image 1: broken piece of guide wire (foreign body) in pulmonary artery shown with arrow.

Image 2: Snare with 3 interlaced loop engaging the foreign body shown with arrow.

Image 3: retrieval of foreign body

Image 4: Foreign body removed from pulmonary artery. 


\section{International Journal of Science and Research (IJSR) \\ ISSN (Online): 2319-7064 \\ Index Copernicus Value (2015): 78.96 | Impact Factor (2015): 6.391}

\section{Discussion}

As the intravascular procedures increase in frequency, the complications associated with their use also increase exponentially. The Intravascular foreign body is a rare but very serious complication of these intravascular therapies. Intravascular foreign bodies most commonly result from embellished central line fragments, but they may originate from many other potential sources and can be iatrogenic or non-iatrogenic [6]. These foreign bodies could be guided wires, catheter fragments, stents; inferior vena cava filters and fractured sheaths [7]. Major factors that can cause mobilization of catheter segments include; improper positioning of the catheter, severing of the catheter, poor connection between the port and the catheter, fatigue of catheter, pinch- off syndrome and damage of the catheter by chemotherapeutic drugs [6,7]. The intravascular foreign bodies can migrate to the heart, pulmonary arteries and other vessels [6]. Their dislodgement in pulmonary arteries can increase the risk of possible complications like infections and thrombus formation [7]. Percutaneous retrieval of these foreign bodies with loop snares is most a successful procedure, as we did in our case, for retrieval of broken catheter from pulmonary artery [6]. Multiple devices, including renal stone retrieving baskets, small balloon catheters and guide wires have been used in the past $[8,9]$. Pigtail catheters are used for repositioning of these foreign bodies which further help in their removal $[6,10]$. Catheter associated intravascular foreign body removal is inevitable, before it leads to very serious complications. Percutaneous endovascular approach for the retrieval of such intravascular foreign bodies is extremely safe and has a high success rate with low morbidity and very less number of procedure related complications as compared to other surgical methods of retrieval described.

\section{References}

[1] Kawata M, Ozawa K, Matsuura T, Kuroda M, Hirayama Y, Adachi K, Matsuura A, Sakamoto S:
Percutaneous interventional techniques to remove embolized silicone port catheters from heart and great vessels. CardiovascIntervTher 27(3), 196-200 (2012)

[2] Turner DD,Sommers SC. Accidental passage of a polyethylene catheter fromcubital vein to right atrium: report of a fatal case. N Eng J Med1954;251:744-745

[3] Fisher RG, Ferreyro R. Evaluation of current techniques for nonsurgical removal of intravascular iatrogenic foreign bodies.Am JRoentgenol1978;130:541-548

[4] GuglielmoMariaActisDato, Anna Arslanian, Paolo Di Marzi , Pier Luigi Filosso, EnricoRuffini. Posttraumatic and iatrogenic foreign bodies in the heart: report of fourteen cases and review of the literature. JThoracCardiovascSurg2003;126:408-414

[5] GabelmannA, Kramer S, Gorich J. Percutaneous retrievalof lost or misplaced intravascular objects. Am JRoentgenol2001; 176 (6): 1509-1513

[6] Liu JC, Tseng HS, Chen CY, Chern MS, Chang CY: Percutaneous retrieval of 20 centrally dislodged Port-A catheter fragments. ClinImaging 28(3), 223-229 (2004)

[7] Carroll MI, Ahanchi SS, Kim JH, Panneton JM: Endovascular foreign body retrieval. J VascSurg 57(2), 459-463 (2013)

[8] Wahi PL, Talwar KK, Sapru RB, Non surgical extraction of a broken catheter sheath lodged in the right atrium, using a Dormia ureteral stone dislodger. $\mathrm{Br}$ Heart J 1980; 44: 349

[9] Brilakis ES, Best PJ, Elesber AA et al (2005) Incidence, retrieval methods, and outcomes of stent loss during percutaneous coronary intervention: a large singlecenter experience. Catheter CardiovascInterv 66:333340

[10] Cheng CC, Tsai TN, Yang CC, Han CL: Percutaneous retrieval of dislodged totally implantable central venous access system in 92 cases: experience in a single hospital. Eur J Radiol 69(2), 346-350(2009)

Image description: JPG images

Video description:

Video 1: correspond to Images 2, 3 and 4 and shows removal of foreign body with multi-loop snare device.

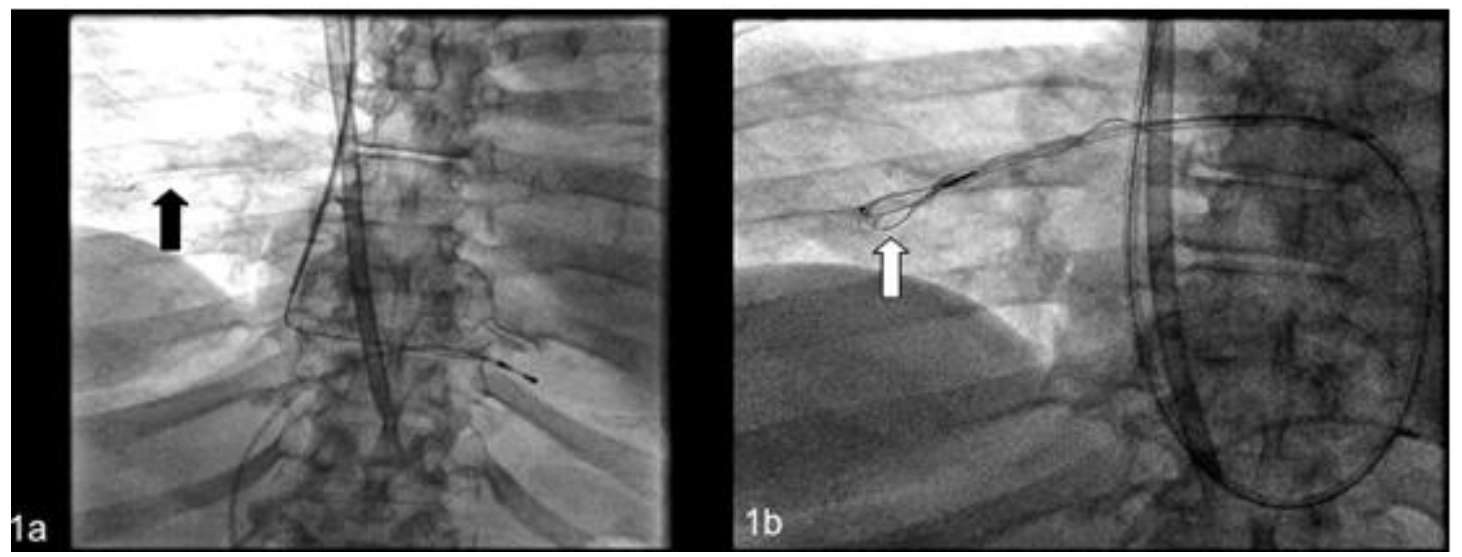

Volume 6 Issue 7, July 2017 www.ijsr.net 
International Journal of Science and Research (IJSR)

ISSN (Online): 2319-7064

Index Copernicus Value (2015): 78.96 | Impact Factor (2015): 6.391

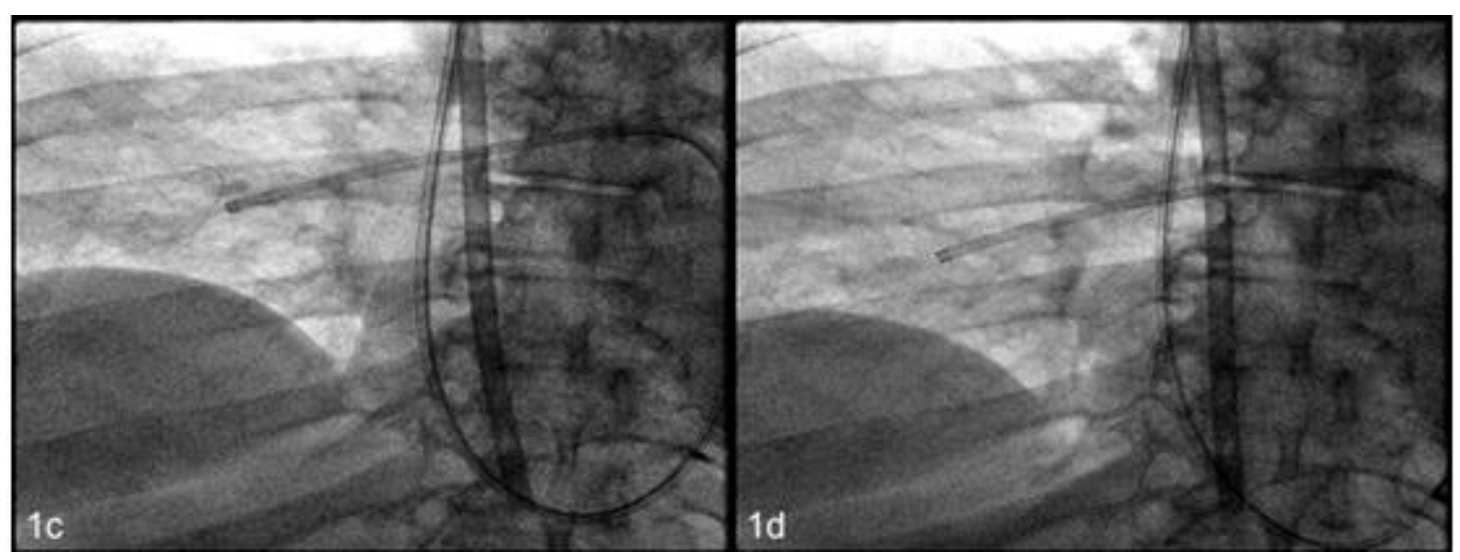

Volume 6 Issue 7, July 2017

www.ijsr.net

Licensed Under Creative Commons Attribution CC BY 